'Scottish Health Policy 1918-1948 - paving the way to a National Health Service?' by Jacqueline Jenkinson.

In The NHS in Scotland: The Legacy of the Past and the Prospect of the Future, ed by Chris Nottingham (Ashgate, 2000), pp. 1-19. 


\title{
1. Scottish Health Policy 1918- 1948 - Paving the Way to a National Health Service?
}

\author{
JACQUELINE JENKINSON
}

\section{Introduction - Creation of the Scottish Board of Health}

The Scottish Board of Health (SBH) was established in 1919 and became the umbrella unit for all the existing components of Scottish health administration, including the Local Government Board for Scotland, the Scottish Insurance Commissioners, and the Highlands and Islands (Medical Services) Board (established in 1894, 1911 and 1913 respectively). The Highlands and Islands Medical Service (HIMS) which now came under SBH control was a distinctive and uniquely Scottish entity: a public medical service established in 1913 to provide medical care for those in the remote regions of Scotland who had often lacked the basic medical services of general practitioner, consultants and clinic facilities due to the difficult nature of their environment. The main aim of the HIMS was to provide a subsidised medical service to the largely crofting communities of the remote Highlands and Islands, an area covering almost half of Scotland, with a population less than one-fourteenth of the country. Many of the special services contemplated in the initial legislation of 1913 were not immediately introduced due to wartime circumstances and it was under the $\mathrm{SBH}$ that the HIMS flourished. For example, as the scheme developed in the $1920 \mathrm{~s}$, general practitioner and nursing services were improved and staffed surgical centres established.

The creation of a Scottish Board of Health in 1919 was not a simple matter. Dr. Christopher Addison the first Minister of Health, piloted the Ministry of Health Bill through Parliament in the months immediately following the end of World War One. Addison rejected the idea of including Scotland in the Health Bill on the grounds that the formation of separate Ministries of Health for Scotland and Ireland would complicate the Bill's passage and involved potential constitutional dangers by raising the 


\section{The NHS in Scotland}

issue of federalism. Addison made clear his views in a letter to the Scottish Secretary, Robert Munro in March 1918: '... a strong section of Scottish opinion will be directed towards making this Bill the occasion for effecting a constitutional change in the Government of Scotland...'

However, Addison's worst fear was that wrangling over Scottish and Irish health and local government reforms would delay, or defeat, the proposals for a new health ministry. Consequently, he restricted his plan for a Ministry of Health to England and Wales. Addison formally disassociated himself from the proposal by Scottish Secretary Robert Munro to the War Cabinet that the existing Scottish Local Government Board and the Scottish Insurance Commission be united in a single health office and that a new Parliamentary Under Secretary to the Scottish Office be appointed. Yet, the Scottish Secretary's plan won the day in Cabinet discussion. One reason why the Cabinet gave in to Munro's pressure and ignored Addison's recommendations was the representations from outside agencies in support of a Scottish clause to the Health Bill:

In Scotland, the volume of opinion in favour of the Bill was very strong, and important deputations from local authorities and labour organisations were unanimous in pressing upon the Secretary for Scotland the urgency of the matter. ${ }^{2}$

Viewed in this light, Scotland could be considered as fortunate in gaining its own health administration. Yet the creation of a separate health administration did not necessarily signify a devolved Scottish health policy. In fact, among the ranks of Scottish MP's there were fears that external control by the Scottish Office, based at Dover House in London, would affect adversely the new Health Board's abilities to solve the pressing problems of Scottish health. Joseph Johnstone Coalition Liberal MP for East Renfrewshire, went as far to state that Scottish people distrusted 'the influence of the Scottish Office in London, and they want to work this Department apart from the paralysing influence of the Scottish Office..., This suggests that there were perceived difficulties in the new system in allocating responsibility between central and Scottish government, as well as a possible divide between the Whitehall-based Scottish Office and the Edinburgh-based Scottish Board of Health. 


\section{Consultation and Policy Formulation}

Under the new Scottish Board of Health (SBH), four Consultative Councils were created as a vehicle to canvass interested opinion from around Scotland on the shape and functions of the new State health agency. One of these was the Consultative Council on Medical and Allied Services which represented the interests of the medical profession. The Council's Interim report (the MacAlister Report) entitled 'a Scheme of Medical Service for Scotland' was issued in November 1920. In essence, the Report recommended that the health service of the nation should be based on the family as the normal unit of health care and that the family doctor (general practitioner) be the focus of this health care. The MacAlister Report recommended the provision of a complete medical service under the SBH through the extension of national health insurance to all dependants of those currently insured. The existing services were to be expanded to cover all forms of health care required, including preventive monitoring of the whole community. The MacAlister Report proposed that the new coordinated medical service should function under the control of a unified system of local authorities. ${ }^{4}$

The Report of the Consultative Council on Medical and Allied Services was received at the end of 1920 for earnest consideration by the SBH. ${ }^{5}$ However, the Report's submission was rapidly followed by a directive from the Treasury restricting planned expenditure in many areas of government for the financial year 1921-1922 and the recommendations of the MacAlister Report were not implemented. Government financial restriction may not have been the sole reason for inaction on the Report. For example, the Report itself was not universally well received by the medical profession. The MacAlister Report of 1920 was an innovative, widê ranging document, which influenced later thinking on the extension of public medical services. ${ }^{6}$

Despite the inability of the SBH to act on the MacAlister Report, the Scottish Consultative Councils continued to meet and produce new policy proposals. In 1921, the Consultative Council on Local Health Administration and General Health Questions issued an interim report advising the reduction in the number of public health authorities in Scotland by creating larger units. ${ }^{7}$ In 1923 , the Council produced a final report on the reform of local government health administration. Its main suggestion was to amalgamate small inefficient local authorities into larger 
units based on county councils and burghs of over 50,000 population. ${ }^{8}$ The recommendations of the Report were not immediately put into operation, but were broadly incorporated into the clauses of the Local Government (Scotland) Act of 1929 .

The Local Government Act of 1929 was the culmination of a series of proposals to reorganise the Scottish system of local government to allow Scottish local authorities to administer public health more effectively. Under the new legislation, Parish Councils were abolished, small burghs lost their autonomous powers and county councils were set up. The reform was very much on the lines of the SBH Consultative Council's earlier proposals. The recommendations of the MacAlister report of 1920 for an enhanced public medical service were based on the assumption that local authorities would be reformed and rationalised. The 1923 Health Administration Consultative Council's suggestions to reduce the number and greatly increase the size of local authorities, were now put into operation.

\section{Administrative Overhaul}

The organisation of the Scottish Board of Health was itself the subject of persistent review in the 1920 s. The $\mathrm{SBH}$ was not run by an administrative civil service like the Ministry of Health, but by a group of expert individuals and career administrators, who, (according to Scottish Secretary John Gilmour in 1928) often brought forward inappropriate and unrealistic policies. This led Gilmour during the 1928 reorganisation of offices debates in Parliament to express in plain terms the problems which (he felt) had arisen in the SBH policy formulation since its creation in 1919:

We have heard much about the technical experts. I am not averse from, nor will any regulation, which I make prevent intercourse between the experts and those responsible for administration... . Parliament must direct policy and control the experts. We know that the expert is often carried beyond the bounds of what is possible in finance or in relation to actual affairs. Is the expert always to have his way? ... if the medical man had his way, he might possibly impose upon Parliament and the country a system - eminently desirable no doubt in itself - but so extravagant, or so much in advance of the times, that Parliament could not tolerate it. ${ }^{10}$

Gilmour's argument is clear. Medical and other expertise within the Board system could lead to the favouring of policy with a strong bias 
towards extended public medical services. Although not specifically mentioned, the 1920 MacAlister Report could fit easily into Gilmour's scathing attack on SBH policy initiatives. This independent strain of opinion within the Board system ran contrary to the existing central government administrative system which had developed under a professional civil service The difference in administrative structure meant that from its very inception there were calls to overhaul the Scottish Board system along Whitehall civil service lines and various attempts throughout the 1920 s to reorganise the SBH. Before the summer recess in 1923, a Reorganisation of Offices (Scotland) Bill was brought before Parliament by the then Scottish Secretary, Viscount Novar. ${ }^{11}$ Although the Bill failed, as did later Reorganisation Bills of 1924 and 1927, the long-awaited reorganisation of the Board system in Scotland finally occurred in 1928. One reason for the delay in implementing structural reform was the high level of domestic political support for the existing Scottish Boards, including the Board of Health.

For example, when the third Reorganisation Bill was put forward in 1927 it was not widely supported in Parliament. William Adamson Labour MP for West Fife ${ }^{12}$ feared that the Government was attempting to subordinate Scottish administration to Whitehall to a far greater extent than previously had been the case and to ... remove from Scotland practically the last vestige of independent government and nationhood, and to have its centre in London. ${ }^{13}$ The Reorganisation Bill of 1927 did not go beyond a Second Reading and a further Reorganisation Bill was introduced by new Scottish Secretary Gilmour in February 1928. In order to deflect the criticism levied at the previous Bill that control was to be shifted to Whitehall, Gilmour inserted a clause specifying that the new Departments were to be situated in Edinburgh.

In Parliament, the Labour opposition expressed the fear that even if Whitehall was not to be the physical location of the new Scottish Departments, power would invariably rest in London. Tom Johnston Dundee Labour MP (and a future Scottish Secretary) stated:

Now we find this Government... deliberately attempting to take away the detailed administration of public affairs in Scotland from bodies of presumably skilled men [sic], who have been nominated because of their knowledge of those particular affairs. It is proposed that the direction of these affairs should be handed over to men who, whatever examinations they might have passed in Oxford or Cambridge, have not proved their 
fitness to conduct those great businesses upon which the lives and happiness of our people depend. ${ }^{14}$

The transformation in 1928 of the Health, Agriculture and Prison Boards into Departments more directly under the control of the Secretary of State aroused misgivings that control of Scottish government affairs within Scotland was at risk. There was also the question of a political divide, as Conservative governments attempted to reorganise the Scottish Boards and were steadily resisted by Labour (and sometimes Liberal) opposition. However, local autonomy was not completely removed, as the 1928 reorganisation allowed the new Departments a degree of independence from the Secretary of State. The absence of shared appointments and any interchange of staff between the Departments also fostered an independent outlook and local loyalty. The powers of the Office of the Scottish Secretary to effect further administrative changes were also constrained by the need to seek Parliamentary approval through the established legislative process.

Although the SBH was itself replaced by a Department of Health for Scotland in 1929, little changed as regards the system of external policy advisers. The work of the Consultative Councils in Scotland continued. For example, in 1933, the Scottish Consultative Council on Medical and Allied Services produced a Report on Hospital Services ${ }^{15}$ which recommended a co-ordinated hospital service. However, as with the MacAlister Report of 1920 this recommendation was set aside until the time was more auspicious for wide ranging health reforms.

\section{The Cathcart Report, 1936}

Further far-reaching proposals were recommended by another advisory committee set up by the DHS. In 1933, the Scottish Health Services Committee was established. It reported three years later. The 1936 Cathcart Report, ${ }^{16}$ built on the recommendations of the 1920 Consultative Council on Medical and Allied Services (MacAlister Report). Indeed, the Cathcart Report explicitly referred to the earlier report as influencing its enquiry. The Cathcart Report proposed a National Health Service for Scotland with a new comprehensive and co-ordinated structure of medical and allied services, and an extension of the general practitioner services to the whole population. It planned for the co-ordination of general practitioner services with existing medical services, such as maternity and infant welfare and school health. 
Reaction to the Report was mixed. The Cathcart Report gained equivocal support from the medical profession. For example, the Scottish BMA supported the notion of increased responsibility for the general practitioner, as did the Royal Colleges. ${ }^{17}$ However, within the medical profession there was also strong resistance to the idea of a state medical service involving government payments for general practitioners. The possibility of a comprehensive state-funded health service was raised in the evidence given before the Cathcart Committee, with both the Scottish Trade Union Council and Glasgow Corporation supporting the idea of a full-time salaried medical service. This proposal was not included in the main report itself, but was raised in a minority recommendation.

In Parliament, the Conservative-dominated National Government did not welcome the Cathcart Report findings with enthusiasm. Scottish Secretary Godfrey Collins glossed over it in the discussions on the annual estimates of the DHS in July 1936. Lack of Government support combined with the predominance of the policy of economy, ensured that of the Cathcart Report recommendations, only the suggested scheme of an extended maternity service was put into operation. Yet the ambitious Cathcart Report helped lay the groundwork for the operation of a distinctive health service suited to Scotland's specific health needs post1948.

The 1937 Maternity Services (Scotland) Act owed much to the findings both of the 1936 Cathcart Report and the 1935 Report of the DHS Committee on Maternal Morbidity and Mortality. The persistence of high maternal mortality rates in Scotland throughout the 1930s (see Table 1 and Figure 1) made this one area where government action was regarded as essential, despite the need to economise in public expenditure. The intention of the Act was to create a public maternity service under local authority control, which would allow midwives, general practitioners and consultant obstetricians to combine to provide comprehensive maternity care. Under the new legislation, payment for the new service was to be recovered by local authorities only where women were in a position to afford such payments. Inability to pay was no longer to be a barrier to an extended range of maternity care.

The DHS investigations of 1935 and the Cathcart Report revealed that existing Scottish maternity services were woefully inadequate. The differences between maternal care in Scotland, and England and Wales and the detrimental effect this had on Scottish maternal mortality was raised in Cabinet by Scottish Secretary Sir Godfrey Collins in May 1936. Collins 
stressed that maternal mortality remained significantly higher in Scotland than in England and Wales. He stated that under the existing maternity services midwives only attended 25 per cent of childbirth cases (in comparison with 60 per cent in England); and that in consequence, doctors continued to play a disproportionate role in maternity cases (with few positive results). Collins also noted that geographic factors had to be given particular consideration in framing new maternity legislation, in view of Scotland's mix of dense urban conurbations and scattered rural communities:

The practical impossibility of applying arrangements - e.g., ante-natal and postnatal clinics - suited to an industrial or urban area, to districts such as the Highlands and Islands, and the varying conditions in regard to maternity practice even as between different urban areas make it essential to frame proposals sufficiently broad and elastic to ensure the development by local authorities of services suited to the circumstances of their areas. ${ }^{18}$

The Maternity Services (Scotland) Act of 1937 was only partially operated in the shorter-term due to the reluctance among doctors to become involved in a scheme, which involved taking direction and (insufficient) payment from local authorities. Only a limited implementation of the scheme could be claimed by the outbreak of the Second World War. However, by June 1943 schemes were in operation in forty-one of the fiftyfive Scottish local authorities.

Other elements in the Cathcart Report influenced wartime proposals for a new National Health Service. For example, a sub-committee of the Cathcart Committee considered health services in the Highlands and Islands. While the sub-committee reported that hospital services in the region remained inadequate, (despite initiatives such as the development of the Northern Infirmary, Inverness) and that much had still to be done regarding nursing services in the area, ${ }^{19}$ overall, the sub-committee was well satisfied with what had been achieved in the region. In fact, the subcommittee proposed that the HIMS, with its unique blend of local and central government control, should be used as a model for the wider application of extended public medical services elsewhere in Scotland. The proposals were incorporated in the main Cathcart Report and re-appeared in the National Health Service White Paper of $1944 .{ }^{20}$ These proposals were dropped after the war, when the idea of a comprehensive health service run 
by the local authority was rejected in favour of a centrally administered medical service.

Despite the existence of the HIMS and a succession of radical proposals emanating from DHS-sponsored committees, Scotland continued to have one of the worst health records of the industrialised world in the inter-war years. Much time and effort had gone into making detailed proposals to improve and extend the health services to meet the needs of the people in a variety of reports including both the MacAlister and Cathcart Reports. Yet few suggestions were put into operation by the end of the 1930s: the overriding desire for economy in public services was partly behind this inaction. However, the great changes in the government of the nation's health, which occurred, between 1946-1948 were conducted in the wake of the Second World War - the most expensive undertaking the country had ever witnessed. This suggests that it was political will (or lack of it), which determined the level and nature of public health provision in the country at any given period. ${ }^{21}$

\section{Wartime Innovations in Social Medicine}

A positive wartime development with regard to Scottish health care was the creation of an extended, and in some respects preventive, State-sponsored hospital service. Such a service had been suggested for a number of years, specifically in the Report on Hospital Services by the DHS Consultative Committee on Medical and Allied Services in 1933. In the event of war breaking out it was assumed there would be huge numbers of civilian wounded. In the spring of 1938, the DHS surveyed the hospitals in Scotland and other buildings, including hotels and public schools, to see where beds could be obtained for the expected air raid casualties. In response to such enquiries, the Emergency Medical Service (EMS) scheme was established in autumn 1938. Through the related Emergency Hospital Scheme, the EMS greatly increased hospital accommodation, expanded the provision of specialist facilities and services, and brought together the various types of hospital authority on a regional basis. The Civil Defence Act of 1939 (Section 50) laid responsibility on the DHS to prepare hospital facilities for civilian casualties as a result of enemy action. Later responsibility was accepted by the Scottish Secretary for the treatment of service personnel in the event of their numbers being too great for the service hospitals to cope. The expected number of casualties never arrived, and by 1941 schemes were put into operation by Wartime Scottish 
Secretary, Tom Johnston, to make use of the increased hospital and nursing home capacity which had been created.

In some respects, wartime Scottish Secretary Tom Johnston (acting under advice from the DHS) can be viewed as a pioneer of the coming National Health Service. In 1941, Johnston introduced the voluntary hospitals waiting list scheme (building on suggestions first discussed by his predecessor John Colville in late 1939). This innovative wartime measure made possible the transfer of patients from voluntary hospital waiting lists to emergency war hospitals. Johnston secured the co-operation of both the voluntary hospitals and general practitioners for this unique measure. The scheme allowed patients to be taken from the long voluntary hospital waiting lists for treatment at the new, largely unused wartime casualty hospitals. The charge to the voluntary institutions was $30 /-$ per patient (irrespective of length of stay). At first, the take-up of this scheme was poor, as it was initially restricted to short-stay surgical patients: In 1941, 2,000 cases from voluntary hospital waiting list were treated in EMS hospitals. In January 1942, the scheme was extended to include all but chronic cases. During 1942 the numbers treated rose to $8,000 .^{22}$ Speaking in the House of Commons in 1945, Johnston described the positive achievements of the scheme in reducing voluntary hospital waiting lists and of its immediate benefits to thousands of patients. ${ }^{23}$ By the middle of 1945 , 32,826 patients had been taken off voluntary hospital waiting lists to be treated in the EMS hospitals. ${ }^{24}$

The 1941 voluntary hospital waiting lists initiative was followed by the creation of the Supplementary Medical Service Scheme in January 1942. This scheme used the hospitals of the Clyde Valley area as centres for the recuperation of hard-pressed wartime industrial workers. ${ }^{25}$ The Clyde Valley hospitals took patients from the nearby Clyde Basin area, (that is, the City of Glasgow and the counties of Lanark, Renfrew and Dunbarton) which housed 40 per cent of Scotland's insured workforce. Much wartime industrial production was carried out in this area. The DHS view was that the health of industrial workers in this part of Scotland could be safeguarded by drawing upon the full range of public and personal medical services, which had come under central control for the first time due to the wartime emergency. Tom Johnston took advantage of the recently constructed (and fortunately under-used) troop hospitals, which came under his control as part of the Emergency Medical Service Scheme, to extend their facilities for specialist services to civilian war workers. 
This Supplementary Medical Service Scheme or Clyde Basin experiment (as it was also known) was an experiment in preventive medical care which involved close co-operation between family doctors, consultants and hospital services. With this initiative, the need for preventive health care, first outlined in the 1920 MacAlister Report, was at last recognised (albeit in a wartime emergency situation). The scheme was initially confined to young industrial workers in West Central Scotland aged fifteen to twenty-five who were in a debilitated state. The focus on younger workers in part reflected an official intention to tackle the growing wartime incidence of tuberculosis. ${ }^{26}$ Later, the scheme was extended to cover workers of all ages in all Scottish counties (except the Highlands). Patients were referred by their own doctors for assessment by the Regional Medical Officers and examined by consultants, where necessary; if a further examination was required, they were admitted to an EMS hospital, or sent for convalescence to one of the auxiliary hospitals.

In 1943, the British Medical Journal reviewing the recentlypublished DHS report on its wartime initiatives in social medicine, Health and Industrial Efficiency, commented approvingly on the Supplementary Medical Service Scheme:

The Englishman may well have begun to wonder why Scotland has been able to initiate a number of experiments in social medicine since war began, and the Department of Health ... acknowledges that the accommodation available in EMS hospitals has made much of the work possible. The Clyde Basin experiment, for example - remarkable because it is directed to maintaining the health and efficiency of young civilian workers - was made practicable because beds were available at two base hospitals - Law and Killearn - in addition to convalescent-home accommodation. ${ }^{27}$

In July 1942, the DHS supplied details of the Clyde Basin experiment for the information of the War Cabinet's Inter-Departmental Committee on Social and Allied Services (the Beveridge Committee). The Beveridge Committee considered public health issues as an integral part of its remit, and took evidence on Scottish health provision as well as National Health Insurance and Contributory Pensions Scheme and Public Assistance. In the DHS Memorandum the Health of War Workers, on file among the Beveridge Committee papers, the preventive element of the scheme was given great emphasis: 
The experiment is designed to safeguard the health of young war workers - largely by preventive measures. It was inaugurated by the Secretary of State issuing to all 'panel' doctors in the area of the Clyde basin a letter in which he appealed for their help in protecting the health of the workers, especially those between the ages of 15 and 25 . He suggested that doctors should take the chance whenever possible of overhauling young patients, and intimated that, to help them with those cases, the Department's Regional Medical Service was available. ${ }^{28}$

The publication of the Report on Social Insurance and Allied Services on 1 December 1942 dramatically changed the climate of opinion regarding peacetime health services. The Beveridge Report ${ }^{29}$ recommended the creation of a single unified social security scheme and in addition, proposed the creation of a free, comprehensive health service. Assumption B of the Report outlined the health requirements of the new Social Services system: Comprehensive health and rehabilitation services for prevention and cure of disease and restoration of capacity for work, available to all members of the community. This stated recommendation bears more than a passing resemblance to the goals of the Clyde Basin experiment (Supplementary Medical Service Scheme) operated by the DHS.

The future shape of Scottish hospital provision became a topic for wartime discussion as part of the wider debate on post-war reconstruction. In October 1943, the DHS Office Committee made a set of proposals, which underlined their commitment to social medicine:

(a) the Supplementary Medical Service Scheme should continue until the introduction of the Comprehensive Health Service;

(b) that the kind of service now given under the Supplementary Medical Service should become a permanent feature of preventative medical service. ${ }^{30}$

These recommendations were later underlined in June 1945, when new Scottish Secretary Joseph Westwood (in recognition of the importance of the extended hospital facilities which had been introduced during the war), pledged to continue to make the additional wartime beds available for the use of the Scottish population. At the start of the war Scotland had 35,331 hospital beds $(21,248$ in voluntary and 14,083 in local authority hospitals), by the end of the war the total had risen to 48,101 . By this measure, a net addition of 12,970 beds remained in use post-war in Scotland. In mid-1946, the DHS announced that the EMS hospitals would continue to be administered by the Department pending the reconstruction 
of the health services. In other words, both the DHS and the Scottish Secretary were committed to a State-run hospital service (including its preventive aspects) for Scotland.

Initiated by wartime requirements, the Emergency Medical Service in Scotland was in peacetime incorporated into a comprehensive service under the direction of the DHS and the Scottish Secretary of State. This transformation was a dynamic initiative, but it was not clear that these wartime ventures would become long-term, hence the DHS were careful not to look beyond immediate post-war need in preserving the Emergency Medical Service (hospital and ancillary) provision.

\section{A Distinct Entity? The NHS in Scotland}

The change in government as a result of the Labour landslide at the July 1945 election also brought an alteration in direction as far as the planned health service for the nation was concerned. A centrally controlled health service was now envisioned rather than a comprehensive municipal service based on the local authority as the unit of control. The legislative measures introduced by the new Minister of Health, Aneurin Bevan in March 1946 and in December $1946^{31}$ by Scottish Secretary Joseph Westwood were significantly altered from those proposed by the wartime National Government. Both Bills sought to nationalise all hospitals and remove health services such as maternal and infant welfare from the local authorities. The Bills also sought to emphasise the development of health centres, centralise control over the distribution of doctors around the country and introduce payment of general practitiòners.

During his introduction to the Second Reading of the NHS (Scotland) Bill in December 1946, Joseph Westwood made great play of the continuities of the new measure with the recommendations of the 1936 Cathcart Report. Westwood had been a member of the Cathcart Committee and he stated that he and six other people (on the eighteen member Cathcart Committee) had at the time signed a reservation stating their belief that a free, comprehensive general practitioner service available to all was the best way forward for the Scottish health services. Despite Westwood's reminiscences, a crucial recommendation contained in the Cathcart Report, that the general practitioner should be the lynchpin to any reorganised health service, was ignored in the new legislation.

Westwood emphasised that Scottish health policy had a long history of State intervention and funding of health care, focused mainly in 
the Highlands and Islands. He identified the Highlands and Islands Medical Service as a forerunner of the planned NHS: I am often asked what will become of that service in future under proposals contained in this Bill... What, in fact, is happening is that the Bill is extending to all Scotland many features hitherto operating in the Highlands and Islands. ${ }^{32}$ Westwood noted that not a single representation against the NHS (Scotland) Bill had been received from doctors working in the HIMS. By implication, those already working in a proto-State medical service saw the benefits of the new proposals for the whole country. The same could also be said for those working under the EMS wartime hospital arrangements in Scotland. The National Health Service (Scotland) Act was passed on 21 May 1947. A little over a year later, on 5 July 1948, the National Health Service came into operation.

\section{Conclusion}

In wartime Scotland, the EMS and its Hospital Scheme was an unrivalled success. By contrast, there was no attempt to create a State-run hospital service based on the EMS elsewhere in Britain. As a result, when proposals were put forward for a comprehensive health service which would include all hospitals, there was less resistance to this in Scotland than elsewhere in the United Kingdom and effective integration was achieved in a relatively painless manner. The work of the EMS hospital services had shown both the medical profession and the public that a State-run hospital service could function smoothly.

The Second World War gave fresh impetus to investigations into the state of public medical care. The War also provided the opportunity to experiment with an expanded range of state health services, especially in Scotland. Yet, in the wake of emergency measures, and the debate on a comprehensive health service which they partly fuelled, there was also clear continuity with pre-war DHS policy initiatives and debates, with inter-war reports on health provision, and the existing Highlands and Islands Medical Service having a formative role to play in shaping the new universal system.

The NHS Scotland legislation seemed to be a compromise between the need for a comprehensive health service, which followed to a great extent the 1946 NHS Act for England and Wales, and yet did not neglect the traditions of independent Scottish health policy. The latter was maintained through the creation of Scottish Hospital Management Boards. 
These had more devolved powers than their counterparts, the English Hospital Management Committees, and crucially, included the government of the prestigious University teaching hospitals. Also, in Scotland, overall administrative control was placed in the hands of the Scottish Secretary and not the local authorities, as was the case in England.

This chapter has illustrated a number of areas relating to policy making and implementation where the Scottish health administration, while itself undergoing change, was able to follow its own agenda. Indeed, this agenda, as a whole, was influenced by particular areas of concern in the health of the Scottish population. The continued vibrancy of the Scottish Consultative Councils in the 1920s and 30s, the creation of distinct policies on maternal welfare (although not completely successful), and the setting up of the Clyde Basin experiment of preventive hospital care, illustrate the continued distinctiveness of Scottish health administration. After a difficult inception, and some inter-war re-organisation, Scottish health services administration was fully based in Edinburgh by the 1930s. After 1948, the NHS in Scotland maintained its separate identity from the Ministry of Health in London, despite the pressures of administrative centralism.

\section{Notes}

1. Public Records Office (PRO), Kew, London PRO MH78/70 Letter from Addison to Munro 19 Mar. 1918.

2. PRO CAB 26/1 Home Affairs Committee, 3rd meeting, 18 July 1918, 'Ministry of Health Bill'.

3. Hansard Parliamentary Debates, House of Commons (HOC), 1 Apr. 1919 vol. 114, column 1146.

4. Scottish Board of Health (SBH) Interim Report of Consultative Council on Medical and Allied Services A Scheme of Medical Service for Scotland (1920), pp.6-7.

5. SBH Second Annual Report, 1920 [Cmd 1319] HMSO, (1921), p.257.

6. Such as in its call for unified local authorities which eventually came with the Local Government (Scotland) Act of 1929.

7. Glasgow Medical Journal (GMJ) 96 (1921) pt. 2, pp.199-200.

8. The Report revealed there were then 201 self-governing burghs in Scotland. 19 of these had a population of less than 1,000 and 108 others with a population of less than 5,000 . It was impossible for such units to individually provide the public health services required by the 1920 s. The Report suggested replacing these units with larger public health authorities of burghs with over 50,000 population and on county councils of a similar size. Reviewing the 1923 report, the British Medical 
Journal (BMJ) revealed it had little chance of early success: 'Apart from vested interests, probably the great majority of public health officers will agree that this small number is far better than the present absurd multiplicity, but it seems doubtful whether a bill to give effect to these proposals has much chance to become law, looking to all the influences which would be ranged against it. Perhaps the report, however, may have the effect of leading to some measure of much needed reform'. BMJ (1923) pt. 2, 18 Aug. 1923, p.300.

9. In response to existing local authority vested interests the population unit was set at 20,000 to create 55 new Scottish local authorities.

10. HOC 9 July 1928, vol. $219 \mathrm{col}$. (1986).

11. House of Lords debates (HOL), Viscount Novar, 30 July 1923, vol. 54, col. 1457.

12. William Adamson MP for West Fife (1910-31), had been the Labour Party's Secretary for Scotland in 1924. He later served as Secretary of State for Scotland 1929-1931.

13. HOC 23 Mar. 1927, col. 346.

14. HOC 5 Mar. 1928, vol. 214, col. 898.

15. Department of Health for Scotland (DHS) Consultative Council on Medical and Allied Services Report on Hospital Services (Edinburgh, 1933).

16. The Scottish Health Services Committee Report became known after its (second) Chairman, nutritionist Edward Provan Cathcart.

17. Both Edinburgh Royal Colleges (Physicians and Surgeons) strongly supported the key role of the general practitioner in the health services in their evidence to the Cathcart Committee. See DHS Committee on Scottish Health Services Report, [Cmd 5208] (1936), pp.152-153.

18. PRO CAB 24/262 CP (36) 128 Memorandum by Scottish Secretary, Sir Godfrey Collins on the extension of maternal health services in Scotland, 7 May 1936.

19. DHS Committee on Scottish Health Services Report, p.230.

20. DHS A National Health Service [Cmd 6502] (1944), p.72.

21. For more on the view that government policy is only influenced by agencies when they tell it what it wants to hear, see Keith Dowding The Civil Service (1995), p.111.

22. Glasgow Medical Journal (New Ser.) 21 (1943) pt. 1, p.18.

23. $\quad B M J(1945)$ pt. 1, p.718.

24. Summary Report by the Department of Health for Scotland Committee on Scottish Health Services Report for the year ended 30 June 1945 (Edinburgh, 1945), [Cmd 6661], p.15.

25. DHS Health and Industrial Efficiency: Scottish Experiments in Social Medicine (1943) [HMSO].

26. PRO MH79/526 Memorandum by Thomas Johnston to Cabinet Home Policy Committee 'Prevention and Control of Tuberculosis', Jan. 1942.

27. BMJ (1943) pt. 1, p.789 Report on the DHS pamphlet Health and Industrial Efficiency.

28. PRO Cab 87/81 War Cabinet Inter-Departmental Committee on Social and Allied Services Memoranda Papers file pp.100-129. Memorandum 112 - DHS 'Health of War Workers', 20 July 1942.

29. War Cabinet Inter-Departmental Committee on Social and Allied Services (Beveridge Report) Social Insurance and Allied Services (1942) [Cmd 6404]. 
30. PRO MH76/603 DHS Office Committee on the 'Demobilisation' of the Emergency Hospital Scheme - Scotland, 13 Oct. 1943.

31. The National Health Service (Scotland) Bill was published on 6 Nov. 1946 accompanied by a White Paper (HMSO Edinburgh, 1946) [Cmd 6946].

32. HOC debates 10 Dec. 1946, vol. 431, col. 1011. 
18 The NHS in Scotland

\section{Table 1}

Comparative Maternal Mortality Rates (per 1,000 births), 1918-1948

\begin{tabular}{|c|c|c|}
\hline Year & Scotland & Eng\&Wales \\
\hline 1918 & 7 & 3.8 \\
\hline 1919 & 6.2 & 4.4 \\
\hline 1920 & 6.2 & 4.3 \\
\hline 1921 & 6.4 & 3.9 \\
\hline 1922 & 6.6 & 3.8 \\
\hline 1923 & 6.4 & 3.8 \\
\hline 1924 & 5.8 & 3.9 \\
\hline 1925 & 6.2 & 4.1 \\
\hline 1926 & 6.4 & 4.1 \\
\hline 1927 & 6.4 & 4.1 \\
\hline 1928 & 7 & 4.4 \\
\hline 1929 & 6.9 & 4.3 \\
\hline 1930 & 6.9 & 4.4 \\
\hline 1931 & 5.9 & 4.1 \\
\hline 1932 & 6.2 & 4.2 \\
\hline 1933 & 5.9 & 4.5 \\
\hline 1934 & 6.2 & 4.6 \\
\hline 1935 & 6.3 & 4.1 \\
\hline 1936 & 5.6 & 3.8 \\
\hline 1937 & 4.8 & 3.3 \\
\hline 1938 & 4.9 & 3.1 \\
\hline 1939 & 4.4 & 2.9 \\
\hline 1940 & 4.2 & 2.7 \\
\hline 1941 & 4.7 & 2.8 \\
\hline 1942 & 4.1 & 2.5 \\
\hline 1943 & 3.7 & 2.3 \\
\hline 1944 & 3 & 1.9 \\
\hline 1945 & 2.5 & 1.8 \\
\hline 1946 & 2.2 & 1.4 \\
\hline 1947 & 2 & 1.2 \\
\hline 1948 & 1.1 & 1 \\
\hline
\end{tabular}


Figure 1

Comparative MMR: Scotland and England and Wales, 1918-48

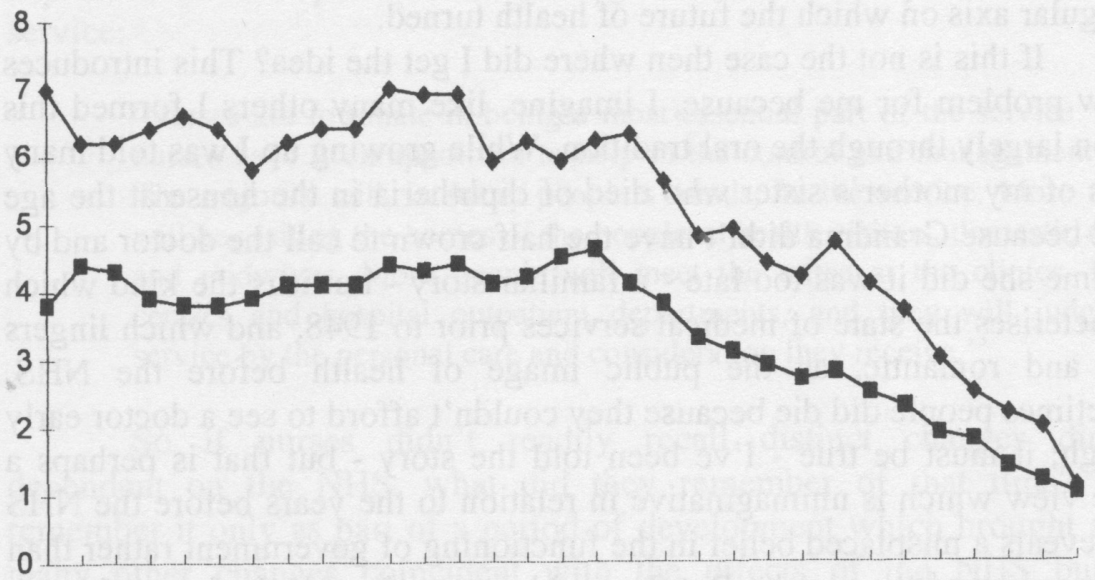

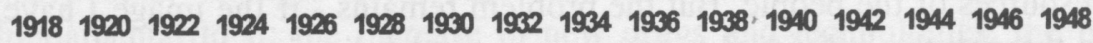

